\title{
Cognitive and Discoursive Features of Speech Etiquette in Corporate Communication
}

\author{
Elena Malyuga ${ }^{1}$, Daria Maksimova ${ }^{1} \&$ Maria Ivanova ${ }^{2}$ \\ ${ }^{1}$ Faculty of Economics, Foreign Languages Department, Peoples' Friendship University of Russia (RUDN \\ University), Moscow, Russia \\ ${ }^{2}$ Maxim Gorki Institute of Literature and Creative Writing, Moscow, Russia \\ Correspondence: Elena Malyuga, Faculty of Economics, Peoples' Friendship University of Russia (RUDN \\ University), 117198,6 Miklukho-Maklay Str. Moscow, Russia. E-mail: en_malyuga@hotmail.com
}

Received: March 19, 2019 Accepted: April 17, 2019 Online Published: May 8, 2019

doi:10.5539/ijel.v9n3p310 URL: https://doi.org/10.5539/ijel.v9n3p310

\begin{abstract}
Today, the cultural, community-driven and individual-specific facets of speech etiquette are discussed in terms of the functional aspects manifested in various types of communication, including corporate interaction. This article analyzes the main cognitive and discoursive characteristics of the British and American speech etiquette from the perspective of cultural, social and role stereotypes, gives a characteristic of the content structure of speech behavior in corporate communication in three main areas - information, evaluation, motivation - and identifies ways to form these values. In order to achieve this goal, the following tasks are to be solved: (1) to determine the functions of speech formulas and their influence on the speech etiquette of British and American businesspeople, and (2) to identify the most outstanding characteristics in the use of formulas of agreement or disagreement in British and American speech etiquette. The article reveals the conditionality of the choice of speech etiquette formulas in the socio-cultural aspect and argues that speech etiquette in corporate communication is characterized by specialized functions and their clear implementation, which is the key to successful communication. The authors conclude that the change of the communicative setting entails the transformation of the register, therefore, the use of other formulas of speech etiquette. Consequently, the transition from formality to individualization of formulas has appeared in the use of formulas of agreement or disagreement in speech etiquette. So, business partners choose formulas based on the appropriateness and acceptability of use in the current setting with a specific interlocutor.
\end{abstract}

Keywords: corporate communication, speech etiquette, speech formulas, speech behavior, politeness

\section{Introduction}

\subsection{The Statement of Problem}

The problem under study is concerned with the specifics of corporate speech etiquette in its comparative perspective and implies careful consideration of British and American speech formulas and their functional interpretation as part of business discourse. To that end, the study aims to pinpoint the functions of English speech formulas used in the corporate environment and identify how one of their specific types-formulas of agreement and disagreement-are manifested against the background of culturally determined aspects of communication. To address these aims, the study relies on the texts published in British and American media outlets, as well as transcripts of corporate spoken and written interactions while also heavily drawing on the theory of politeness proposed by Brown and Levinson (1987). The relevance for the politeness theory investigation is clearly seen even in modern linguistics. Acquisition and knowledge of politeness rules helps to achieve communicative goals, that is why the analysis of politeness theories as a basis for further investigation of speech etiquette is widely spread among modern researchers.

Modern linguistics focuses more and more on the relationship of such concepts as language and culture. Scientists are divided into three main groups upon that issue. The first group supposes that language is an integral part of culture and a linguistic picture of the world forms because of it (Spolaore \& Wacziarg, 2016). Fullness and abundance of the world picture by each individual language is the result of the perception of the world by every nation. 
Thus, having analyzed the examples of the use of speech formulas and their division into semantic and pragmatic combinations, we can assume that the formulas of agreement and disagreement exist as part of a complex verbal interaction with the function of "comment". Mostly it is a comment on the previous statement made by the speaker. The comment function will directly affect the communicative attitudes of the interlocutors. The formulas of agreement or disagreement influence the success of communication and determine its trajectory.

\subsection{Research Questions}

Therefore, three research questions will be formulated as follows:

- What is the functional interpretation of speech etiquette as part of business discourse?

- What do the formulas of speech etiquette prescribe in corporate communication?

- What is the influence of the theory of politeness on the speech etiquette?

\subsection{Gap}

The issue deserves new research as the categories of agreement and disagreement have not yet been studied in the context of corporate communication; the authors create a hierarchy of speech formulas basing on up-to-date oral and written language material.

\section{Literature Review}

The phenomenon of corporate culture is considered in terms of the generally accepted concept of culture, but it means the understanding of the corporation as a complicated social system with certain values and norms, according to which the company operates (Trevino \& Nelson, 2016).

Speech etiquette is understood as the rules of speech behavior developed in this society and the system of speech formulas of communication. Linguistics pays more and more attention to the theory of communication. The problems of speech behavior of people in general enter into the foreground, as well as the problems of individual linguistic personality and its formation. Expressive means are studied comprehensively considering national and cultural factors. There is a deep and constant interaction between language and reality, between the world of language and the world around us (Moravcsik, 2016).

In the framework of constant internationalization and business activities, the knowledge and understanding of the basics is the key to successful transactions, negotiations and deals. Understanding the specifics of corporate communication also influences the inflow of foreign clients and business partners.

This article considers approaches to the study of the Brown-Levinson's politeness theory, as well as opinions of scholars concerning formulas of speech etiquette in corporate communications.

Formanovskaya (1982) identified specialized functions of speech etiquette, based on the communicative function - the phatic, regulatory, emotional-volitional and cooperative functions (Formanovskaya, 1982, p. 27).

In business communication, the speech of interlocutors should follow certain rules of conversation, otherwise the parties will not achieve consent. Both oral and written behavior of partners should conform to the stereotypes of specific social and cultural backgrounds. Moreover, the speech etiquette is a significant aspect of any national culture. Speech behavior, different communicative formulas are derived from traditions, experience, national identity and national lifestyle.

In the works of Hossein Sadeghoghli and Masoumeh Niroomand (2016), the authors overview the impact of Brown and Levinson theory on the process of learning English language and come to conclusion that power relationship, social distance, and degree of imposition constrain communicative action universally, but the value of these factors vary from context to context. So, in other words they confirm the original idea of Brown and Levinson that in order to have a succesfull communication it is important to know cultural and social background as well as be familiar with politeness strategies. Another linguist-Kitamura Norika (2000) investigates in her works the types of etiquette interactions that are not covered by politeness theory. The researcher noted that there are some phenomena that were not mentioned by the original theory by Brown and Levinson, as for instance: the principal speaker introduces a statement gradually, rather than all in one turn, and the hearer shows his/her involvement by back-channelling or by summarising the principal speaker's statement.

There were also critiques of the theory. For example, in the works of Eelen Gino (2001), the linguists claim that in the context of Brown and Levinson theory politeness is understood as strategic conflict-avoidance, and this is manifested in the view that the main social role of politeness is in its ability to function as a way of monitoring potential aggression and rudeness between different conversational parties. However, the actual reality only proves that politeness is used not only to avoid aggression but to maintain self-esteem, cooperate with a partner, 
orientate him to common values etc.

Theoretical foundation of this study relies on previous research concerned with the issues of (1) discourse as a notion indissolubly related to sociocultural and pragmatic factors (Coulthard, 2014); (2) the cognitive approach to communication research suggesting that linguistic activity is one of the types of cognitive activity and language events could be understood adequately only in the context of other cognitive processes, such as knowledge representation, memory, attention and perception (Hewes, 2013); (3) pragmatics as a framework for speaker-listener interaction within a certain temporal, special and situational context (Leech, 2016); comparative British English vs American English studies considering the role of stereotypes in people's communicative behavior (Malyuga, 2011); the theory of politeness and its critique highlighting the variability of "face" as a cultural and linguistic phenomenon (Salmani Nodoushan, 2012; Sifianou, 2010); the theory of speech acts and its focus on the pragmatic potential and illocutionary force of speech formulas in their direct dependence on temporal and social frames (Searle, 1985; Burkhardt, 2010).

\section{Method}

\subsection{Study Material}

The study uses official British and American mass media texts and transcripts of business negotiations, debates and business letters as research material. In particular, there are 56 extracts of dialogues and monologues analysed. 28 examples of business letters in both American and British variants (taken from Wolverhampton Business English Corpus http://metashare.elda.org), and 28 examples from scripts from American and British English corporate discourse: (1) HBO and Google meeting in Silicon Valley panel discussion, (2)America's Economic Outlook Debates 2017, (3) GE Digital Partner Day Ways We Win Panel Discussion, and other video and audio transcripts representing corporate discourse.

The sample draws on the transcripts of business meetings and discussions recorded at multinational companies such as Google, HBO, GE, Acceleration Partners, AmLaw, EB-5 Capital. The obtained examples were also analyzed in light of the culturally-driven specifics of oral and written communication inherent in British and American linguacultures.

\subsection{Study Methods}

The key procedure behind the present research is the continuous sampling method further supplemented by the stylistic analysis of the resulting sample. The continuous sampling method is used to select examples for analyzing and illustrating theoretical grounds: writing out all the examples of the analysed phenomena from the original text in a row.

The following methods are also used in this study: descriptive, comparative, contextual, cognitive and discoursive methods.

To distinguish and study the main notions, we use the descriptive method:

The descriptive method is the main method of language research that identifies specific linguistic phenomena and then, consistently describes them in terms of their structure and/or functioning.

Further on, we investigate the phenomena of agreement and disagreement in corporate discourse by the means of contextual analysis:

Contextual analysis is used to study the functional specifics of linguistic phenomena and their meanings. It is the text analysis (a fragment of a text or a sentence) in which this phenomenon is used.

The practical part of our research is achieved by the means of method of continuous sampling.

To identify some specifics in the examples we use comparative method which is a system of research methods of both: related and multi-structural languages, that identifies common and distinctive features and characteristics in these languages.

\section{Cognitive and discoursive method}

Within this article we will follow cognitive approach that shows the results of the investigation not only at the level of the text, but also of the context, being a kind of mediator in the study of language structures and extralinguistic factors.

Cognitive and discoursive method relies on the unity of the word and the concept, language and thinking, linguistic and extralinguistic factors. The cognitive approach is an interface of the relations between discourse and the society as a complex. The work focuses on those aspects of the structure and role of not only personal but also social cognition that directly account for the most fundamental properties of the production and 
comprehension of discourse. Discourse analysis of the study implies the usage of the speech formulas in social life that represent the analysis of language in its widest sense.

\section{Results}

Corporate discourse is a kind of institutional communication that ensures general professional activity. Corporate discourse forms a sense of belonging and participation in the activities of the establishment and the positioning of it for both internal (establishment) and external (non-establishment) audiences. The disparity of opinions regarding the language influence on culture does not negate the fact that each individual corporate culture has its own rules and regulations of the speech etiquette. We carry out speech activity while communicating, while the society puts forward certain rules for the implementation of different types of speech activity (Petrey, 2016). These rules constitute the concept of speech etiquette or conversational etiquette.

According to linguists, speech formulas can be divided into 2 groups - semantic and pragmatic (Table 1).

Table 1. Hierarchy of speech formulas

\begin{tabular}{llll}
\hline Word Combinations & & & \\
\hline Semantic Group & & Pragmatic Group & \\
Collocations & Idioms & Proverbs & Routine etiquette formulas \\
\hline
\end{tabular}

The formulas belong to a pragmatic group when each of them possesses its own pragmatic potential and it is obliged to influence the recipient. The formulas of conversational etiquette contain specialized functions. Totally, scientists distinguish five functions of speech etiquette.

1) Phatic function. This function is used to establish and maintain contacts between speakers. First of all, the speaker should gain the attention of the interlocutor.

2) Appellative function. As the name implies, the target is to motivate the interlocutor for further conversation.

3) Conative function. It is related to interpsychic indicators, for example, the choice of the form of address or greeting, the formality or informality of communication, etc. That is, orientation to the status and social position in the communicative act.

4) Voluntative function. Expression of will towards the interlocutor.

5) Emotive function. This function determines the choice of the appropriate register depending on the emotion we want to express.

All of them are based on a single fundamental function - the communicative one.

Etiquette speech formulas are stable expressions that are accepted within a society. They exist in both written and spoken speech and in all language genres. Etiquette formulas are often phraseological entities, prepared linguistic means. The basic principles in using etiquette formulas are not about politeness only, but also about the compliance with the register of the communicative situation.

Differences in speech registers change speech behavioral models of communicators, therefore, influence the choice of etiquette formulas. The speaker or the writer can change their style of communication depending on the following factors:

1) time;

2) place;

3) social status (of both the speaker and the addressee);

4) communicative competence (of both the speaker and the addressee).

Etiquette rules can vary depending on whether the topic of conversation is sad or happy. There are special rules of speech behavior related to the place of conversation (lunch, office, business meeting) (Hallahan et al., 2007). The multiplicity and diversity of such situations contributes to the identification of speech types. It will be possible to implement them adequately, if the definition and selection of appropriate ways of their linguistic expression are correct. One way or another, the choice of certain etiquette formulas will be determined by the social role of the communicator, his or her status, the norms of speech behavior adopted in this environment, as well as the cultural norms.

The presence of the functions of speech etiquette in communication is considered as a prerequisite for successful 
communication, through which people transmit information to each other, answer questions or ask them, perform certain speech actions (address, welcome, thank, etc.). It is necessary to remember that there are many synonymical formulas of speech etiquette, and use the whole spectrum. It helps to achieve the desired action from the communicator. For example, if a British person wants to respond to the greeting of the interlocutor, he will say optimistically: "Fine, thanks" or "Not so bad, thanks". The volume of synonymy can vary in different languages. Moreover, unlike Americans, the British try not to use foreign or unknown (special) words, jargon, vulgarisms, vernaculars, dialects unnecessarily. In American English, it is increasingly possible to meet the so-called professional and corporate jargon used by the representatives of specific professions. American English is the language of large, multinational companies.

In the research of the speech etiquette, at first the attention is paid to polite forms of address, but we suppose the expression of rudeness should not be ignored, especially if speech aggression is disguised.

In recent years, businesspeople express an increased interest towards the problems of business etiquette. It is especially important to consider these factors when interacting with foreigners. A foreigner's mindset could be not only specific, but completely different from the mindset of a person of another culture. In this case the word "mindset" reflects the cultural stereotypes of business partners and their countries and it is an unforgivable mistake to ignore it.

The problem of stereotypical speech behavior was analysed in terms of interpretation of the rules of communicative conduct (Murphy, 2016, p. 56). The use of speech stereotypes by the British, on the one hand, and Americans, on the other, could be considered as cultural, social and role stereotypes of speech behavior.

It is a well-known fact that nowadays people of different professions and different cultures are more and more involved in the process of internationalization of obtaining a particular end product. In such a situation, it has become an axiom that a businessman will not profit if he cannot communicate with people of other professions. Talking about the qualities of an individual, we try to highlight the emotional-volitional sphere, character, intelligence, education. But the speech portrait gives the most overwhelming characteristics of the personality.

Today, there is no need to leave the country or even leave your workplace, because each of us can contact a large number of people of different nationalities and professions. And all the time it is necessary to consider the specifics of the communicative setting (conference, meeting, presentation, negotiations, etc.).

Speech etiquette, of course, follows the norms of behavior and communication. And if politicians, lawyers, officials or people, whose professions are associated with communication, do not possess the speech etiquette, it means they are professionally ineptitude. Misunderstanding of the specifics of language functioning in various professional spheres, characteristics of spoken and written forms of speech, stylistic features of business correspondence, speech helplessness are frequent among the representatives of different professional communities.

As for the principle of politeness, it is the most important one in communication, because it determines the strategy of speech behavior. Considering the principle of politeness, the verbal behavior of the interlocutors is a special kind of communicative interaction, based on respect.

The society is always heterogeneous. Given the social stratification, we should not forget the specific set of etiquette means and common neutral expressions. Thus, entering into communication with another social environment, on the one hand, it is necessary to choose stylistically neutral means of communication, and some means of communication used only in this environment, on the other. Indeed, difficult linguistic and social information is hidden in the speech etiquette.

It can be argued that, having mastered the basic rules of speech etiquette, business partners will be able to avoid conflict situations; they achieve mutual understanding, earn universal respect and not insult their interlocutors with their behavior. In business communication, the speech of interlocutors should follow certain rules of conversation, otherwise the parties will not achieve consent. Both spoken and written communication should conform to the stereotypes of specific social and cultural backgrounds.

\section{Discussion}

In the English-speaking society, communication between educated people is conducted at three levels of politeness - official, neutral and familiar. English speech etiquette is a set of special words and expressions that provide a polite form of English speech, as well as the rules according to which these words and expressions are used in various situations of communication. Speech etiquette makes speech polite regardless of its content. English speech etiquette has a long and very authoritative tradition, so much so that any deviation from speech etiquette is perceived as a manifestation of bad manners, impoliteness or deliberate rudeness. 
Each level of politeness possesses its own style of speech. At the formal level of politeness, polite communication takes place in a formal setting, where neither age, sex or personal dignity are paramount, but the social status of the interlocutors and their current posts. The official level of courtesy is obligatory in institutions, organizations, business, education, healthcare, etc. Social conditionality of actions, affairs and intentions of interlocutors is expressed in the style of their speech behavior which is formed differently than speech behavior at home, with friends or at casual communication with a stranger. A deviation from the official level of politeness in a formal setting is perceived as a clear lack of respect for the interlocutor and can lead to conflict and even severance of their official relations. Therefore, it is necessary to strictly adhere to the official level of politeness where it is necessary and foreseen by etiquette.

At the neutral level of politeness, the polite communication is carried out between strangers, as well as between those people who are not in an official or familiar relationship.

The familiar level of politeness is typical for communication in the family, friends and buddies.

We suppose that the formulas of agreement and disagreement can be divided into the following types:

1) full agreement with the opponent's opinion;

2) partial acceptance of the opponent's opinion;

3) soft refusal to acknowledge the opinion of the opponent as the right one (the soft no);

4) rude denial (often occurs in a dialogue between two employees of the same company).

We observed the shift of the speech register in corporate communication. Often, corporate speech etiquette requires to agree with the opponent at first, emphasizing his or her ideas, and then express a different opinion. However, it is not always the case, especially in spoken speech. Communicators are unable to restrain emotions during the conversation; therefore, an involuntary speech register becomes more informal, and the standard formula of agreement, then the criticism are not used.

As for TV or programs that broadcast to a large audience, the standard formula of disagreement works. It's demonstrated well in the example from the transcript of America's Economic Outlook debates (Intelligence Debates, 2018):

"I am kind of going to go against of what Stephen Moore has said".

In the written correspondence of employees, we can see an absolutely different picture. From email correspondence:

"On many levels, I totally agree with the way you do business".

"My supervisor, (NAME), and I strongly disagree about the necessity of my having access to customer profiles".

"I rarely disagree with a customer, Mr. Linton, but you don't have time, as you suggest, to think about it".

"If you disagree with anything I've written, let me know by next Friday".

"If you disagree with the retention schedules please indicate your suggested charge".

"I'm sorry to have to disorder with you, but we cannot wait, in my opinion".

"I realize every organization is different, but I respect your insight and experience. Thank you for your time during the call, but we will pass this time".

It should be noted that regardless of whether the communication takes place between the representatives of British or American cultures, communication between employees of one or more corporations will occur and will obey the framework of the theory of politeness.

This is a classical theory of politeness, which is based on the socio-cultural behavior of communicators. The basic concept of this theory is the "face" concept, which refers to the positive social value belonging to each member of the corporation and the society. Brown and Levinson (1987) distinguish two main parts in this concept: "positive" and "negative". A positive face is a dignified, positive image, which is claimed by communicators in the course of speech interaction, literally the desire to be desired by others. By means of negative politeness, Brown and Levinson define apologies, linguistic and non-linguistic reverence, tone softening, mechanisms of de-personification (the speaker and the listener distance themselves from the dialogue).

Positive politeness encompasses such voice tools, which indicate that the speaker's wishes coincide at least partially with the wishes of the listener, formulas of agreement and disagreement are such kind of means. 
To implement positive politeness the most important is to emphasize the fact of the speaker and listener joining the same group, which can be manifested in "thee"-communication, if the language has the opposition of "thee"/“you"-communication, in informal appeals, use of jargon or slang, code switching and ellipsis.

In order to understand the degree of de-formalization of speech etiquette in modern corporate discourse, it is necessary to consider the subtypes of politeness in details.

1) Negative politeness (distancing) is a well-developed set of strategies, needed to demonstrate to the listener the recognition of his or her independence, personal autonomy, to assure of the absence of intentions to violate the existing borders between him or her and the addressee from the speaker's part, and, if necessary, to minimize the influence on him/her. These strategies are aimed at social distancing, creation of communicative barriers and borders. The main guideline for communicators is the fact of absence of bonding, which is typical for communication between employees of different companies who are engaged in talks, don't exchange experience, are not partners, but still obliged to show respect for each other.

There are a number of strategies of negative politeness in English culture, for example, when communication should be expressed indirectly: "Could you please pass me the report next to you?" It is necessary to minimize the degree of intervention:" I just want to ask you if I can borrow a tiny bit of paper". Necessary to apologize: "I'm sorry to trouble you, could you tell me the time?" etc. So, we can conclude that the dominant feature of the English communicative culture is remoteness.

Positive politeness (bonding). Unlike politeness of distancing, politeness of bonding is aimed at reciprocity, understanding and reducing the distance. Linguistic realization of positive politeness in many respects is the verbal behavior of close people who show interest in each other in everyday communication (Brown, 2015, p. 327). The purpose of positive politeness is to mask the threat to the positive face of the interlocutor. The speaker uses special means to show that he or she respects the desire of the interlocutor to have his or her own opinion. Positive politeness is typical for businesspeople and top managers in the American culture. They often use the following expressions to mask the threat to the positive face in conversation with partners: "Definitely!", "Absolutely agree", "Right you are", "That's a good point", "Okay, I'm happy with that for now", "Yes, I'd go along with that", "Yes, definitely".

Thus, the trend to change the formulas of speech etiquette according to the speech situation is significant only for spoken communication in the company, between its employees. When it comes to panel discussions, exhibitions, debates, conferences and interviews, people try to adhere to the classical formulas of agreement and disagreement (Figure 1).

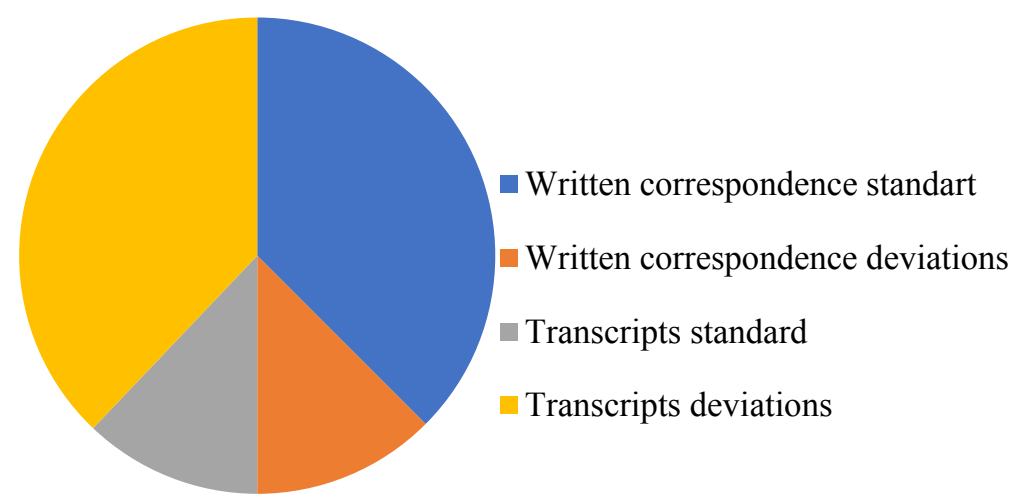

Figure 1. Formulas of agreement and disagreement

$60 \%$ of the examples (56 monologues and dialogues) comply with the norms of speech etiquette. The opponents were allowed to speak, nobody interrupted their monologue, then the speakers agreed with a part of their opinion and expressed their own.

\section{Conclusion}

This study was concerned with the specifics of British and American corporate speech etiquette and speech 
formulas, more particularly their functional interpretation as part of business discourse. The paper outlined the key functional prerequisites for the use of various speech formulas, which mostly procede from the peculiarities and conventionalities of culturally accepted communication standards in BrE and AmE. This research contributes to the analysis of the current state of corporate etiquette by illuminating a tendency to informalize communication between employees of the same corporation, who are in the same social situation. However, the dependence of the speech etiquette on the place and time of communication is clearly traced, as well as on other social factors described in the article.

By the means of the cognitive and discoursive analysis this study achieves some generic conclusions e.g., etiquette formulas are dependent upon cultural background and some are specific to settings: deviations from the standard agreement formulas in modern American corporate discourse.

All these factors of the cognitive and discoursive analysis affect the development of etiquette formulas and their semantics.

The formulas of speech etiquette prescribe the need to start any objections with the formulas of agreement, thereby combining it with the formulas of disagreement. In order to express disagreement such expressions are recommended: "I see what you're saying but I think..."; "I respect your point but from my perspective (or but in my opinion)"; "I take your point but that isn't the way I see it; instead, I think that..."; "True, that is a fair point, but I have to say I disagree...".

In written communication (business letters), 21 out of the 28 considered examples (75\%) strictly follow the standard formulas of agreement and disagreement (to accept the opinion of the interlocutor, then criticize). In spoken communication, $75.8 \%$ of the formulas deviate from the standard and accepted formulas. In these examples, a shift towards the informalization of communication takes place.

\section{Acknowledgments}

The publication has been prepared with the support of the "RUDN University Program 5-100.

\section{References}

Brown, P. (2015). Politeness and language. In J. Wright (Ed.), The international encyclopedia of the social and behavioral sciences (pp. 326-330). Elsevier. https://doi.org/10.1016/B978-0-08-097086-8.53072-4

Brown, P., \& Levinson, S. C. (1987). Politeness: Some universals in language usage (Vol. 4). Cambridge University Press. https://doi.org/10.1017/CBO9780511813085

Burkhardt, A. (Ed.). (2010). Speech acts, meaning and intentions: Critical approaches to the philosophy of John R. Searle. Walter de Gruyter.

Coulthard, M. (2014). An introduction to discourse analysis. London, UK: Routledge. https://doi.org/10.4324/9781315835884

Evans, D., Hopkins, A., \& Potter, J. (2000). Management gurus. Pearson Education Limited.

Formanovskaya, N. I. (1982). Russian speech etiquette: Linguistic and methodological aspects. Moscow, Russia: Nauka.

GE Digital. (2016). GE Digital partner day ways we win panel discussion. Retrieved from https://www.youtube.com/watch?v=QTrZvLmwXE4

Gino, E. (2001). A Critique of Politeness Theories. St. Jerome Pub.

Hallahan, K., Holtzhausen, D., Van Ruler, B., Verčič, D., \& Sriramesh, K. (2007). Defining strategic communication. International Journal of Strategic Communication, 1(1), 3-35. https://doi.org/10.1080/15531180701285244

Hewes, D. E. (2013). The cognitive bases of interpersonal communication. New York, NY: Routledge. https://doi.org/10.4324/9781315044415

Intelligence Debates. (2018). Unresolved: America's economic outlook. Retrieved from https://www.intelligencesquaredus.org/debates/unresolved-americas-economic-outlook

Kitamura, N. (2000). Adapting Brown and Levinson's "Politeness" theory to the anlaysis of casual conversation (pp. 163-169). In Proceedings of ALS2k, the 2000 Conference of the Australian Linguistic Society. Melbourne: University of Melbourne.

Leech, G. N. (2016). Principles of pragmatics. London, UK: Routledge. https://doi.org/10.4324/9781315835976 
Malyuga, E. N. (2011). Gender factor in national varieties of English. International Journal of English Linguistics, 1(1), 30. https://doi.org/10.5539/ijel.v1n1p30

Moravcsik, J. M. (2016). Thought and language. London, UK: Routledge. https://doi.org/10.4324/9781315524139

Murphy, M. L. (2016). (Un) separated by a common language? Are American/British differences unimportant? English Today, 32(1), 56-59. https://doi.org/10.1017/S0266078415000619

Petrey, S. (2016). Speech acts and literary theory. London, UK: Routledge. https://doi.org/10.4324/9781315537436

Sadeghoghli, H., \& Niroomand, M. (2016, February). Theories on Politeness by Focusing on Brown and Levinson's Politeness Theory. International Journal of Educational Investigations, 3(2), 26-39.

Salmani Nodoushan, M. A. (2012). Rethinking face and politeness. International Journal of Language Studies, 6(4), 119-140.

Searle, J. R. (1985). Expression and meaning: Studies in the theory of speech acts. Cambridge University Press.

Sifianou, M. (2010). On the concept of face and politeness. In F. Bargiela-Chiappini \& D. Kádár (Eds.), Politeness across cultures (pp. 42-58). Springer. https://doi.org/10.1057/9780230305939.0008

Spolaore, E., \& Wacziarg, R. (2016). Ancestry, language and culture. In V. Ginsburgh, S. Weber \& P. Macmillan (Eds.), The Palgrave handbook of economics and language (pp. 174-211). London, UK: Palgrave Macmillan. https://doi.org/10.1007/978-1-137-32505-1_7

Talks at Google. (2017). HBO's Silicon Valley. Retrieved from https://www.youtube.com/watch?v=QOXup 8 chEoY\&t $=513 \mathrm{~s}$

Trevino, L. K., \& Nelson, K. A. (2016). Managing business ethics: Straight talk about how to do it right. John Wiley \& Sons.

\section{Copyrights}

Copyright for this article is retained by the author, with first publication rights granted to the journal.

This is an open-access article distributed under the terms and conditions of the Creative Commons Attribution license (http://creativecommons.org/licenses/by/4.0/). 